p-ISSN 1693-9484, $e$-ISSN : 2621-8313

Majalah Ilmiah Bahari Jogja (MIBJ)

Vol. 18 No. 2, Juli $2020 \quad$ (101-117)

DOI : $10.33489 /$ mibj.v18i2.219

(C2020 Sekolah Tinggi Maritim Yogyakarta

\title{
Perizinan Pembangunan Tersus/Terminal Khusus (Studi Kasus CV Bina Lestari Jaya) Di Pangkalpinang Bangka Belitung
}

\author{
Rizki Dwi Wardoyo ${ }^{1}$, Supartini ${ }^{2 *}$, Vivid Dekanawati ${ }^{2}$ \\ ${ }^{1}$ D3 Sekolah Tinggi Maritim Yogyakarta \\ ${ }^{2}$ Sekolah Tinggi Maritim Yogyakarta, Jl. Magelang KM 4.4, Yogyakarta 55284, \\ Indonesia \\ * Corresponding Author. E-mail : supartini.amy @ gmail.com. Telp: 081578800014
}

\begin{abstract}
Abstrak
Kegiatan bidang pelayaran dibedakan menjadi dua, pelayaran niaga dan bukan niaga. Guna mendukung sarana angkutan laut diperlukan prasarana berupa pelabuhan. Pelabuhan merupakan tempat pemberhentian/terminal kapal setelah melakukan pelayaran. Di pelabuhan kapal melakukan berbagai macam kegiatan, seperti naik turun penumpang, bongkar muat barang, pengisian bahan bakar, dan air tawar. Guna menunjang kegiatan usaha untuk kepentingan sendiri, maka dapat dibangun Terminal Khusus (Tersus), Untuk pembangunan tersus, CV Bina Lestari Jaya melakukan koordinasi dengan pihak pemerintah dan menyusun konsep secara matang, mengurus perijinan yang memiliki tahapan dan persyaratan yang cukup rumit, karena membutuhkan survey dengan data yang akurat, baik penetapan lokasi, studi kelayakan baik di darat maupun di laut/perairan. Perlu dipertimbangkan pula aspek ekonomi, efisiensi, dampak lingkungan dan K3 (Kesehatan dan Keselamatan Kerja). Selanjutnya melakukan studi kelayakan didampingi tim tehnis Distrik Navigasi Kelas 1 Palembang. Dalam penelitian ini, penulis menggunakan metode penelitian kualitatif dengan pendekatan diskriptif.
\end{abstract}

Kata Kunci: Perijinan, Pembangunan Terminal Khusus (Tersus).

\begin{abstract}
The activities of the shipping sector are divided into two, commercial and noncommercial shipping. In order to support sea transportation facilities, infrastructure in the form of a port is needed. The port is a stop / terminal of the ship after a cruise. At the port the ship carries out a variety of activities, such as the ups and downs of passengers, loading and unloading of goods, refueling, and fresh water. In order to support business activities for its own interests, a Special Terminal (Tersus) can be built. For the construction of the tersus, CV Bina Lestari Jaya coordinates with the government and prepares concepts thoroughly, takes care of licensing which has quite complicated stages and requirements, because it requires a survey with accurate data, both location determination, feasibility studies both on land and at sea / water. It also needs to consider the economic aspects, efficiency, environmental impact and $K 3$ (Occupational Health and Safety). Furthermore, a feasibility study was accompanied by a Palembang
\end{abstract}


Class 1 Navigation District technical team. In this study, the authors used a qualitative research method with a descriptive approach.

Keywords: Legal lermit, special terminal construction.

\section{PENDAHULUAN}

Pelabuhan merupakan tempat pemberhentian kapal setelah melakukan pelayaran. Di pelabuhan kapal melakukan berbagai macam kegiatan, naik turun penumpang, bongkar muat barang, pengisian bahan bakar dan air tawar. (Bambang Triatmodjo, 2008: 67).

Guna menunjang kegiatan usaha tertentu untuk kepentingan sendiri, maka dapat dibangun terminal khusus (tersus), pengertian terminal khusus merupakan terminal yang letaknya di luar Daerah Lingkungan Kerja (DLKr) dan Daerah Lingkungan Kepentingan (DLKp) pelabuhan yang merupakan bagian pelabuhan terdekat guna melayani kepentingan sendiri sesuai usaha pokoknya.(UU RI No 17 Tahun 2008, pasal 1).

Pengelolaan tersus dilakukan pemerintah provinsi, pemerintah kabupaten/kota, atau Badan Usaha Pelabuhan (BUP) sebagai pengelola terminal khusus. (Pasal 9A PM 73, 2014).

PT. Persero Pelindo II Cabang Pangkalbalam, Bangka Belitung membangun tersus komoditas ekspor, timah, sawit, karet. Pembangunan tersus bertujuan mendukung dan meningkatkan perekonomian, khususnya komoditi ekspor daerah. Menurut Tito Guntoro saat ini kegiatan bongkar muat barang domestik dan penumpang kapal berada dalam satu pelabuhan, sehingga dibutuhkan pengembangan pelabuhan, guna memisahkan kegiatan bongkar muat barang domestik dan terminal penumpang.

Pembangunan tersus komoditi ekspor sudah mendapatkan dukungan dari berbagai pihak karena dinilai efektif, untuk pengiriman komoditas ekspor. Dengan adanya tersus, pendistribusian komoditas ekspor daerah ke berbagai negara lebih efektif, efisien, karena selama ini antrian sandar kapal kargo cukup panjang.

Kondisi ini menjadi masalah tersendiri bagi eksportir dan pengguna jasa pelabuhan dalam meningkatkan ekspor, karena harus menunggu kapal sandar untuk memuat komoditas ekspor. (www.radarbangka.co.id/berita/detail/pangkalpinang/34421/pelindo-bangunpelabuhan-khusus-komoditas-ekspor.html )

Kesimpulannya, dengan meningkatnya jasa pelayanan bongkar muat merupakan implikasi dari laju pembangunan nasional dan pemerataan hasil-hasil pembangunan ke seluruh pelosok tanah air, sehingga PT (Persero) Pelindo II Cabang Pangkalbalam dengan pemerintah Provinsi Bangka Belitung dan pihak swasta merencanakan pembangunan tersus guna kelancaran kegiatan.

\section{KAJIAN LITERATUR}

Perencanaan pengembangan pelabuhan sedikit berbeda dengan perencanaan pembangunan prasarana kegiatan lainnya, mengingat peran dan fungsi pelabuhan 
yang sangat kompleks, oleh sebab itu perencanaannya dapat merefleksikan fungsi dan perannya. Perencanaan pelabuhan dikaitkan dengan aktifitas dan prasarana yang menunjang keberlangsungan pelabuhan.

Seorang perencana pelabuhan (port planner), memimpin dan mengkoordinasi berbagai keterkaitan disiplin ilmu menjadi satu output perencanaan sesuai tolok ukur/acuannya. (Sumardi dkk,2000:8).

Perencanaan pembangunan pelabuhan terkait dengan berbagai disiplin ilmu dan mempunyai kompleksitas cukup besar, sehingga berbagai disiplin ilmu masuk dalam perencanaan pelabuhan, lihat tabel di bawah:

Tabel 1 : Disiplin Ilmu Terkait Perencanaan Pelabuhan

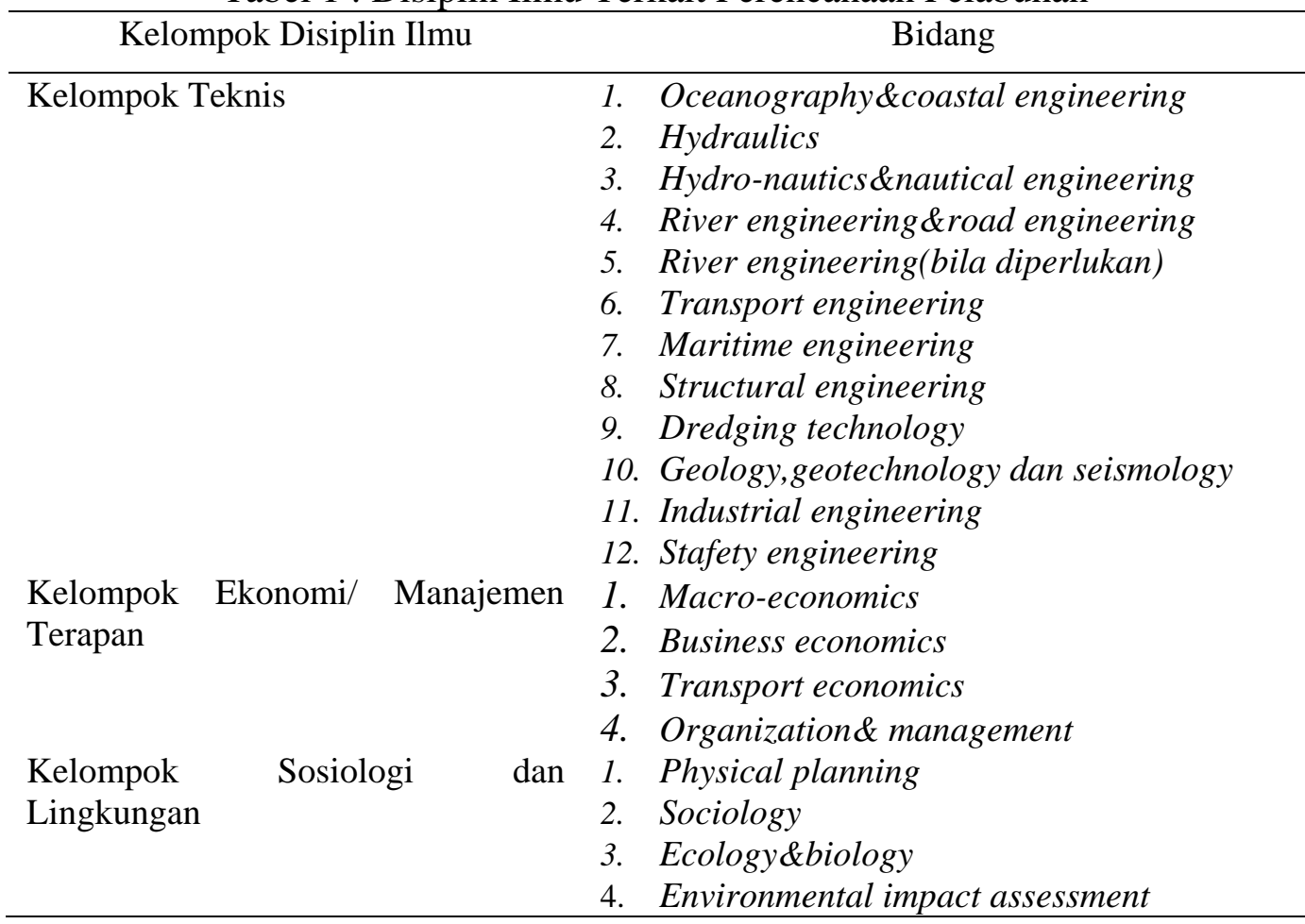

Sumber : Sumardi dkk, (2000: 8)

Konsep perencanaan pelabuhan, secara fisik pelabuhan berfungsi sebagai jembatan penghubung antara transportasi darat dan laut. Fungsi dan peran pelabuhan berkembang dari masa ke masa selaras dengan perkembangan aspekaspek yang terkait.

Latar belakang keberadaan dan pengelolaan serta pengoperasian pelabuhan beragam, sehinggga beragam pula pendekatan terhadap konsep/teori pengembangan perencanaan. (Sumardi dkk, 2000: 9)

Perencanaan pengembangan dilaksanakan dalam jangka panjang dan komperhensif, diarahkan pada pelabuhan sebagai prasarana umum yang menunjang perkembangan sosial ekonomi daerah dan nasional. Oleh karena itu, perencanaan pelabuhan tidak hanya diperuntukkan bagi pengembangan daerah dan nasional tetapi juga internasional. Perencanaan pelabuhan merupakan proses yang kompleks, mengaitkan seluruh aspek dan tahapan dalam siklus aktifitas pelabuhan. 
Secara skematis gambaran interaksi seluruh aspek dalam rantai kepentingan perencanaan dapat dilihat pada skema di bawah.

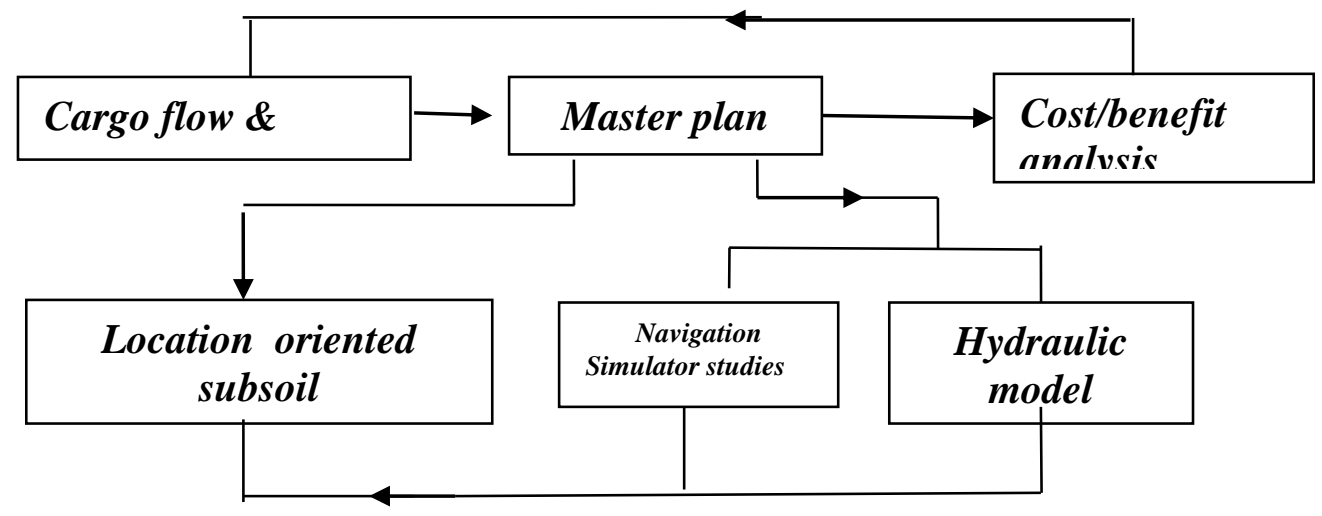

Gambar 1 : Perencanaan Pelabuhan (Master Plan)

Sumber : Sumardi dkk ( 2000: 10)

Pemilihan lokasi pembangunan pelabuhan terdiri daerah pantai dan daratan, tergantung dari berbagai faktor kondisi tanah dan geologi, ke dalaman dan luas daerah perairan, perlindungan terhadap gelombang, arus dan sedimentasi, daerah daratan cukup luas untuk menampung barang yang dibongkar muat, akses jalan untuk transportasi dari daerah industri.

Pemilihan lokasi mempertimbangkan berbagai faktor, tetapi faktor-faktor di atas tidak dapat semua terpenuhi, maka diperlukan kompromi guna mendapatkan hasil optimal. Tinjauan daerah perairan menyangkut luas yang diperlukan untuk alur pelayaran, kolam putar (turning basis), penambatan dan berlabuh. (Bambang Triatmodjo, 2008:73)

Perencanaan pembangunan terminal meliputi: analisis geografi dan lingkungan sosial ekonomi, lingkungan alam, perencanaan fasilitas pelabuhan dan pemecah gelombang (break water). Pembangunan tersus membutuhkan perijinan kepada instansi terkait, berdasarkan ketentuan perundang-undangan yang berlaku.

Menurut PM. Nomor 73 Tahun 2014 pasal 1, persyaratan memperoleh penetapan lokasi tarsus meliputi:

1. Salinan surat izin usaha pokok dari instansi terkait.

2. Letak lokasi yang sudah diusulkan dilengkapi dengan koordinat geografis yang digambarkan dalam peta laut.

3. Studi kelayakan yang memuat:

a. Rencana volume bongkar muat bahan baku, peralatan penunjang dan hasil produksi.

b. Rencana frekuensi kunjungan kapal.

c. Aspek ekonomi berisi tentang efisiensi dibangunnya tersus dan aspek lingkungan.

d. Hasil survei yang meliputi hidrooceanografi (pasang surut- gelombang, ke dalaman dan arus), topografi titik nol (benchmark) lokasi pelabuhan yang dinyatakan dalam koordinat geografis. 
4. Rekomendasi dari Syahbandar pada pelabuhan terdekat berkoordinasi dengan kantor Distrik Navigasi setempat mengenai aspek keamanan dan keselamatan pelayaran.

5. Rekomendasi Gubernur dan Bupati/walikota setempat mengenai kesesuaian rencana lokasi terminal khusus dengan rencana tataruang wilayah provinsi dan kabupaten/kota.

6. Laporan keuangan perusahaan minimal 1 (satu) tahun terakhir yang diaudit oleh kantor akuntan publik terdaftar.

7. Referensi bank nasional atau bank swasta nasional yang memiliki aset paling sedikit Rp. 50.000.000.000.000,- (lima puluh triliyun rupiah).

8. Direktur jendral melakukan penilaian dan menyampaikan hasil penilaian pemenuhan persyaratan.

9. Izin Pembangunan dan Pengoperasian Terminal Khusus

Permohonan izin pembangunan dilengkapi dengan persyaratan sebagai berikut:

a. Persyaratan Administrasi, meliputi :

1) Akte Pendirian Perusahaan.

2) Surat Izin Usaha Pokok dari instansi terkait.

3) Nomor Pokok Wajib Pajak (NPWP).

4) Bukti penguasaan tanah.

5) Bukti kemampuan finansial.

6) Laporan keuangan perusahaan minimal 1 (satu) tahun terakhir yang diaudit oleh kantor akuntan publik terdaftar.

7) Referensi bank nasional atau bank swasta nasional yang memiliki aset paling sedikit Rp. 50.000.000.000.000. ( lima puluh triliyun rupiah).

8) Proposal rencana tahapan kegiatan pembangunan jangka pendek, jangka menengah, dan jangka panjang.

9) Rekomendasi dari Syahbandar pelabuhan terdekat setelah mendapat pertimbangan dari kepala Distrik Navigasi.

b. Persyaratan Teknis Kepelabuhan berdasarkan PM No 73 Tahun 2014 Pasal 7, meliputi:

1) Studi kelayakan memuat antara lain:

a) Rencana volume bongkar muat bahan baku, peralatan penunjang dari hasil produksi, serta frekuensi kunjungan kapal.

b) Aspek ekonomi dan finansial yang berisi tentang efisiensi dibangunnya terminal khusus dan aspek lingkungan.

c) Aspek keselamatan dan keamanan pelayaran di terminal khusus.

d) Hasil survei mengenai pasang surut dan arus.

e) Tata letak dermaga.

f) Perhitungan dan gambar kontruksi bangunan pokok.

g) Hasil survei kondisi tanah.

h) Hasil kajian keselamatan pelayaran termasuk alur pelayaran dan kolam pelabuhan.

i) Batas-batas rencana wilayah daratan dan perairan dilengkapi titik koordinat geografis serta rencana induk yang ditetapkan sebagai daerah lingkungan kerja dan daerah lingkungan kepentingan tertentu. 
j) Kajian lingkungan berupa studi lingkungan yang telah disahkan oleh pejabat.

k) Sistem dan prosedur pelayanan di terminal khusus.

1) Tersediannya sumber daya manusia dibidang teknis pengoperasian pelabuhan yang memiliki klasifikasi dan kompetensi yang dibuktikan dengan sertifikat.

10. Izin Pembangunan Dan Pengoperasian Tersus Memuat tentang:
a. Data perusahaan.
b. Spesifikasi teknis dermaga tambat.
c. Batas-batas rencana wilayah daratan dan perairan dilengkapi titik koordinat georgafis.
d. Rencana induk terminal khusus.
e. Batas waktu penyelesaian pembangunan.
f. Kewajiban pemegang izin.
g. Pencabutan izin.
h. Jangka waktu berakhirnya izin.

11. Daerah Lingkungan Kerja Dan Daerah Lingkungan Kepentingan Digunakan Untuk:
a. Lapangan penumpukan.
b. Tempat kegiatan bongkar muat.
c. Alur pelayaran dan perlintasan kapal.
d. Olah gerak kapal.
e. Keperluan darurat.
f. Tempat labuh kapal.
Rencana induk pengembangan terminal khusus paling sedikit memuat tata letak fasilitas di sisi air dan di sisi darat.

\section{METODE PENELITIAN}

Metode penelitian yang digunakan adalah penelitian kualitatif dengan motode deskriptif, prosedur penelitian yang menghasilkan data deskriptif berupa kata-kata tertulis atau lisan dan perilaku dari orang-orang yang diamati, dengan melakukan eksplorasi dalam rangka memahami dan menjelaskan masalahmasalah yang menjadi fokus masalah penelitian ini.

Pendekatan ini diarahkan pada latar dan individu secara holistik (utuh), jadi tidak mengisolasikan individu atau organisasi ke dalam variabel atau hipotesis, tetapi perlu memandangnya sebagai bagian dari sesuatu keutuhan. (Bogdan dkk. dalam Moleong, 2005).

Penelitian deskriptif bertujuan, pertama mengetahui perkembangan sarana fisik tertentu atau frekuensi terjadinya suatu aspek fenomena sosial tertentu; tujuan kedua untuk mendeskripsikan secara terperinci fenomena sosial tertentu. (Singarimbun dan Effendi, 1983).

Metode pengumpulan data dan informasi dilakukan menggunakan metode observasi, dengan cara mengadakan pengamatan dan pencatatan, dalam arti luas observasi tidak hanya terbatas pada pengamatan secara langsung maupun tidak langsung. 
Metode interview dan dokumentasi, pengumpulan data dengan cara tanya jawab secara langsung dengan responden lisan dan tertulis serta mengumpulkan data dari suatu lembaga yang relevan, data tersebut sudah jadi.

Metode analisa deskriptif merupakan suatu laporan terbatas pada apa yang nampak dan terdengar saja dan bersifat deskriptif. Untuk menambahnya menjadi analitis, peneliti mengeksplor lebih dalam guna mengetahui apa yang terdapat di belakang fakta dari yang terlihat atau terdengar tersebut. Dengan kata lain harus meneliti hubungan sebab akibat antara fakta dan meneliti fakta yang menyertai terjadinya suatu peristiwa. (Abu Achmadi dkk, 2005). Sedangkan menurut Selltiz, dalam Purjiono (2019) "Analizing the result of descriptive study, the process of analysis includes: coding the interview replace, observation and tabulating the data, yang artinya proses analisis deskriptif meliputi memberikan kode jawaban wawancara, observasi dan tabulasi data.

\section{HASIL DAN PEMBAHASAN}

Mengacu Undang undang Pelayaran, Peraturan Pemerintah tentang Kepelabuhan serta sosialisasi instruksi Dirjen Perhubungan Laut No.UM.008/2/2/DJPL/14, 10 Januari 2014, surat edaran Dirjen Perhubungan Laut No.UM.003/44/16/DJP, 20 Februari 2016 Tentang Penertipan Legalitas Terminal Khusus (Tersus) dan Terminal Untuk Kepentingan Sendiri (TUKS) diharapkan segala bentuk kegiatan kepelabuhanan sesuai dengan peraturan perundangundangan yang berlaku.

CV Bina Lestari Jaya salah satu BUP yang melakukan pembangunan tersus, menunjuk dan memberi kuasa kepada perusahaan pelayaran PT. Karya Cipta Bangka Lancar untuk mengurus perijinan tersus tersebut.

Dengan studi kelayakan, dapat menjadi referensi bagi pejabat yang berwenang dalam mengambil keputusan yang bijak sehingga pembangunan tersus dapat berjalan dengan lancar. Untuk mengurus perijinan pembangunan tersus ada beberapa tahapan, tahapan pertama yaitu:

1. Penetapan Lokasi Tersus

Penetapan lokasi menjadi hal utama, guna memberikan efektifitas dibangunnya tersus di wilayah tersebut, sehingga penetapannya harus tepat guna.

Persyaratan penetapan lokasi tersus meliputi:

a. Membuat surat permohanan penetapan lokasi dan survei

b. Legalitas perusahaan, dibuktikan dengan surat izin usaha pokok.

Pengajuan ijin pembangunan tersus CV. Bina Lestari Jaya yang bergerak usaha pokok pertambangan, wajib memiliki IUP (Ijin Usaha Pertambangan) dan OP (Operasi Produksi) yang dikeluarkan oleh Gubernur /Bupati/Walikota.

c. Bukti penguasaan tanah atas lokasi perencanaan tersus yang dibuktikan dengan sertifikat/sewa/izin pinjam pakai.

2. Pengurusan Perijinan Ke Pemerintah Daerah.

Berdasarkan UU No. 9 Tahun 2015 Tentang Perubahan atas UU No. 23 Tahun 2014 Tentang Kewenangan Gubernur, setelah dilengkapi semua persyaratan penetapan lokasi tersus, kemudian berkas permohonan dimasukkan ke Dinas 
Perhubungan. Selanjutnya Dinas Perhubungan menurunkan tim teknis untuk mensurvei lokasi yang diajukan dan mengeluarkan berita acara guna disampaikan kepada Gubernur sebagai pertimbangan dalam mengeluarkan rekomendasi perizinan penetapan lokasi tersus.

Rekomendasi Gubernur, ditembuskan kepada Bupati/walikota dan diketahui oleh tim BKPRD (Badan Koordinasi Penetapan Ruang Daerah ) Provinsi, terkait tata ruang wilayah (TRW) Provinsi/Kabupaten/ Kota.

Rekomendasi gubernur digunakan pihak perusahaan untuk membuat studi kelayakan, hasilnya dikaji ulang tim teknis dari Otoritas Pelabuhan Pangkalbalam sebagai persyaratan mendapatkan rekomendasi dari pejabat Otoritas Pelabuhan.

3. Studi Kelayakan

Studi kelayakan ini sebagai persyaratan teknis dalam perijinan pembangun an dan pengoperasian tersus, dikaji dalam studi kelayakan meliputi :

a. Rencana bongkar muat bahan baku, peralatan penunjang dan hasil produksi.

b. Rencana frekuensi kunjungan kapal, aspek ekonomi yang berisi tentang efisiensi dibangunnya tersus.

c. Hasil survey hidro oceanografi, meliputi:

1) Survei pasang surut gelombang, ke dalaman arus (bathimetri)

2) Hasil survei berbentuk peta

3) Penentuan titik pilot station ( koordinat)

4) Penentuan titik turning basin (koordinat)

5) Benchmark (titik nol) dermaga minimum 3 (tiga) titik koordinat.

Kegiatan penyusunan dokumen studi kelayakan dan upaya pengelolaan tersus dijadikan acuan operasional berdasarkan : a). Aspek kenavigasian, b). Kepelabuhanan, c). Pelayaran, d). Keselamatan, kesehatan, lingkungan, e). Kelangsungan kehidupan perekonomian, f). Mencapai keserasian dan keseimbangan, g). Mengendalikan pemanfaatan sumberdaya alam secara bijaksana, e).Mewujudkan pembangunan pendapatan daerah.

Pembangunan loading port, dengan strategi kemitraan, dari kunjungan lapangan tidak mudah mendapatkan persetujuan pemerintah daerah dan masyarakat setempat untuk kegiatan investasi, pengelolaan dan pengoperasian tersus. Namun masyarakat asli daerah setempat, memberikan rambu, asalkan kerjasama atau payback period, distribusi dimanfaatkan untuk kemitraan dengan tokoh penduduk setempat dalam kegiatan usaha. Pada prinsipnya penduduk setempat bisa merasakan manfaat dari kegiatan tersebut

Sosialisasi pihak perusahaan dengan mempresentasikan kegiatan yang dilakukan di Desa Tanjung Tuing dan tanggung jawab sosial kepada masyarakat dengan menswadayakan masyarakat setempat.

Strategi kemitraan pengelolaan tersus bisa dilihat pada gambar di bawah ini. 


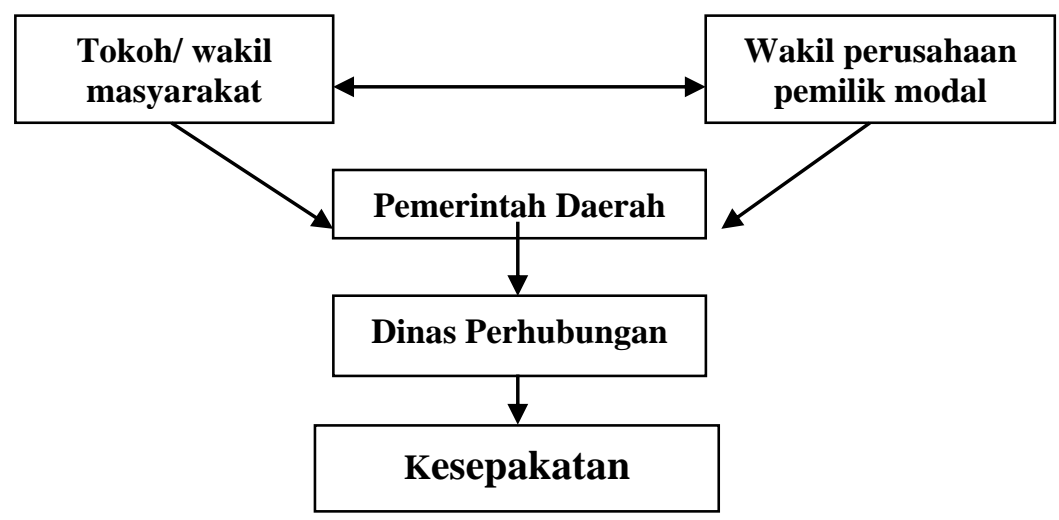

Gambar 2: Strategi Kemitraan Pengelolaan Tersus Tanjung Tuing. Sumber : PT. Karya Cipta Bangka Lancar

Hasil sosialisasi dibuktikan dengan menandatangani berita acara oleh perusahaan dan masyarakat.

Dalam pembangunan tersus membutuhkan pertimbangan dari berbagai aspek, agar pemanfaatan tersus maksimal, yang perlu diperhatikan adalah:

1. Aspek Ekonomi, tujuan menganalisa berbagai dampak dari kegiatan di dermaga Tanjung Tuing, agar mendapatkan efektifitas pengangkutan melalui dermaga tersebut.

Pembangunan dan kegiatan operasional tersus, akan terjadi kontak antara dua bidang sirkulasi transport yang berbeda, transportasi darat dan laut.

Optimalisasi operasional merupakan tolok ukur keberhasilan pembangunan tersus yang diharapkan tidak berdampak secara fisik berupa ancaman kerusakan ekologi, berupa kerusakan lahan, biologi, dan pencemaran, serta bertujuan meningkatkan kesejahteraan masyarakat guna menunjang kehidupan ekonomi, meminimalisir dampak negatif. Pembangunan berkelanjutan bertujuan mengembangkan potensi yang telah digarap sebelumnya, sering disebut sebagai pengembangan (Improvement).

2. Efisiensi Pembangunan Tersus, untuk menganalisa pengembangan lokasi pelabuhan Tanjung Tuing menjadi tersus, digunakan sebagai stockpile dan bongkar muat hasil penambangan CV. Bina Lestari Jaya, dapat mengefisienkan kegiatan bongkar muat dan pengangkutan hasil tambang, dapat menekan cost dan mempengaruhi harga jual.

3. Lingkungan

Lingkungan menjadi pertimbangan penting dalam pembangunan tarsus, perusahaan wajib dan berusaha meminimalisr dampak negatif yang terjadi, sebagai contoh udara, air, yang berasal dari beberapa aspek: dampak kegiatan transportasi, dampak kegiatan dermaga tersus yang mempengaruhi fungsi 
lingkungan serta kehidupan manusia, baik dalam jangka pendek maupun jangka panjang.

4. Keselamatan Dan Kesehatan Kerja (K3)

Kegiatan operasional pelabuhan memiliki karakteristik khusus, padat teknologi, padat investasi, resiko/bahaya tinggi, maka pengelolaan kegiatan pelabuhan memerlukan konsentrasi lebih disemua aspek, teknologi, efisiensi dan aspek keselamatan dan kesehatan kerja. Dalam komitmen mencegah terjadinya kecelakaan kerja, CV. Bina Lestari Jaya melengkapi karyawan dengan Alat Pelindung Diri (APD), peralatan keselamatan kerja yang standar, serta menyelenggarakan safety education kepada karyawan baru.

Organisasi manajemen keselamatan dan kesehatan pelabuhan dipimpin oleh seorang kepala operasional pelabuhan, bertanggung jawab terhadap K3 semua pekerja.

Peralatan yang digunakan dalam K3 sebagai APD meliputi :

a. Alat pelindung diri : 1).Safety shoes (sepatu safety, 2). Safety helmet (helm pelindung), 3). Ear plug (alat peredam), 4). Safety glove (sarung tangan), 5). Safety glasses (kacamata pelindung), 6). Masker, 7). Racun Api, 8). Pelampung

b. Peralatan Perlengkapan K3, meliputi: 1). APAR (Alat Pemadam Api Ringan/Tabung Pemadam), 2). Safety lamp (lampu penerangan), 3). Tandu.

c. Pembinaan K3

Dalam pembinaan K3, CV. Bina Lestari Jaya menjaga komitmen guna mendukung efisiensi dan produktifitas yang ditargetkan, maka ditingkatkan K3 dengan baik,

dalam rangka pencegahan kecelakaan selama kegiatan sehingga tidak terjadi kecelakaan (zero accident).

Langkah-langkah pembinaan K3 dengan cara: 1). Penyuluhan K3 dilaksanakan semua bagian kerja dengan waktu dan jumlah yang direncanakan. 2). Safety talk, dilakukan setiap gilir kerja atau awal shift guna membahas yang dikerjakan, bahaya, peralatan yang dikenakan dan cara penanganan bila terjadi bahaya. 3). Safety Training, pembinaan K3 dengan pelatihan terprogram sesuai kondisi dan kebutuhan. 4). Safety Inspection, inspeksi K3 efektif dilakukan dalam rangka pembinaan K3 di lapangan secara rutin, berkala dan bersama. 5). Safety Investigation, upaya pembinaan K3 melalui investigasi kejadian nearmiss/kecelakaan/ kejadian berbahaya, guna mengetahui penyebab dari kecelakaan, selanjutnya dikoreksi agar kejadian yang sama tidak terulang lagi. 6). Safety Meeting, pertemuan K3 terencana dan rutin, membahas permasalahan berkaitan dengan K3 dapat didiskusikan untuk mencari solusi. 7). Pemantauan Lingkungan Kondisi Kerja, lingkungan kerja dilakukan pemantauan dengan cara pengukuran/pengujian untuk mengetahui sejauh mana lingkungan kerja tidak menggangu kesehatan pekerja, seperti: a. Kondisi debu, b. Kondisi kebisingan, c. Kondisi pencahayaan, d. Kenyamanan kerja.

5. Take Over Lahan

Tahap pembebasan lahan dan take over lahan memiliki resiko tinggi, sehingga diharapkan terhindar dari permasalahan sengketa lahan. Status kepemilikan dan penggunaan lahan merupakan aspek yang diteliti untuk administrasi lahan, 
keluasan lahan, dengan meneliti hal berikut: a. Take over IUP CV. Bina lestari Jaya seluas 4.9 hektar, b. Akses jalan diperlukan $\pm 9 \mathrm{~km}$, c. Lebar badan jalan \pm $6 \mathrm{~m}$, d. Bahu jalan $\pm 1 \mathrm{~m}$ kanan-kiri.

Kondisi jalan merupakan jalan urukan tanah merah bebatuan yang digunakan masyarakat pergi ke kebun, laut serta akses jalan yang dipergunakan masyarakat ke desa/pemukiman penduduk. Keadaan jalan bisa dilihat pada gambar di bawah ini.

Gambar 3: Akses Jalan ke Tambang \& Kawasan Hutan Lindung.

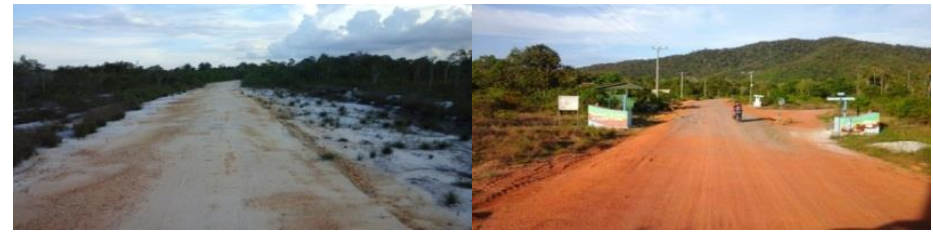

Sumber : Dokumentasi Peneliti

6. Pembangunan Infrastruktur

Studi kelayakan infrastruktur dermaga telah ada, sehingga pemanfaatan infrastruktur dengan cara merenovasi dan perawatan fasilitas seperti:

a. Pembangunan renovasi dermaga untuk sandar kapal,

b. Pemasangan tiang border untuk mengkat tali pada saat kapal sandar di dermaga,

c. Pemasangan tali tross darat.

Struktur rancangan dermaga bisa dilihat pada gambar di bawah ini: Gambar 4: Struktur Rancangan Dermaga
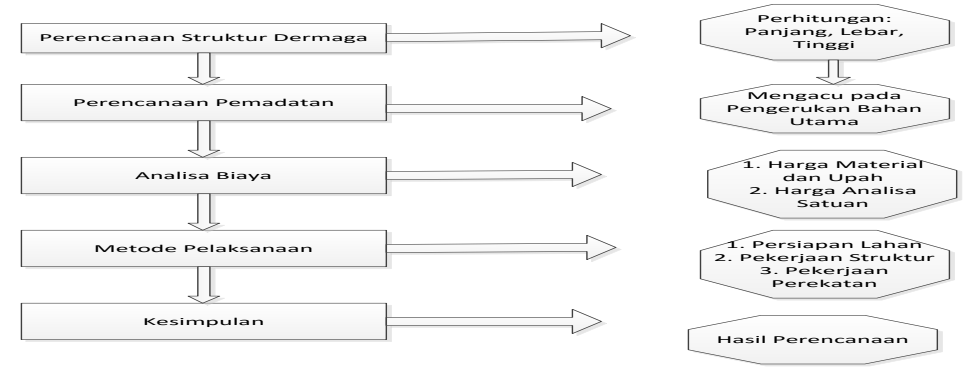

Sumber : Diolah Peneliti

Pembanguanan dan renovasi dermaga membutuhkan tenaga kerja, tenaga kerja yang dilibatkan dalam proyek pekerjaan dibagi dua kategori, pertama tenaga kerja siap pakai untuk posisi-posisi kunci, kedua tenaga kerja belum siap pakai, kemudian dilatih khusus sesuai dengan jabatan/kegiatan yang dibutuhkan, tenaga umum merekrut tenaga kerja lokal sebagai community development atau kearifan lokal.

\section{Rancangan Pembangunan Tersus}

Pada tahapan ini ada beberapa fasilitas yang dibangun dan diperbaiki mengingat kondisi dermaga sebagian sudah mengalami pengikisan.

a. Dasar Rencana 
b. Tersus yang terletak di luar DLKr dan DLKP Pelabuhan yang merupakan bagian dari pelabuhan terdekat untuk melayani kepentingan sendiri sesuai dengan usaha pokoknya. Terminal memiliki prinsip dasar: rancangan dermaga, kolam perairan, volume, panjang, lebar, ke dalaman perairan.

c. Fasilitas Alur Pelayaran

Tersus dioperasikan guna melayani kapal/tongkang dengan muatan maksimal 250 feet. Struktur kapal/tongkang yang tambat di terminal dengan beecing, ramp door.

Sebagai persyaratan lain pihak perusahaan membuat peta lokasi untuk mendukung kelancaran pembangunan tersus, dapat dilihat pada gambar di bawah ini.

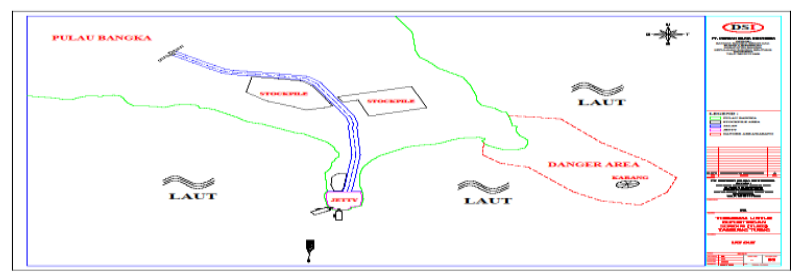

Gambar 5 : Blue Peta Lokasi Tersus CV. Bina Lestari Jaya Sumber : PT. Karya Cipta Bangka Lancar

d. Gambar Kontruksi Bangunan Tersus CV. Bina Lestari Jaya

Gambar kontruksi bangunan Jetty, dipergunakan untuk mengetahui susunan, tata letak dalam perancangan tersus CV. Bina Lestari Jaya, dapat dilihat gambar di bawah.
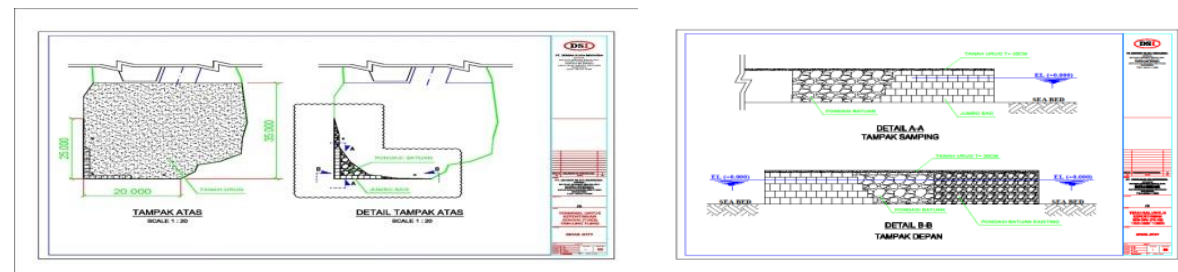

Gamabr 6: Kontruksi Jetty Tampak Pandangan atas dan Samping.

Sumber : PT. Karya Cipta Bangka Lancar

Pembangunan dan pengembangan tersus CV. Bina Lestari Jaya, direncanakan guna memenuhi kebutuhan kelancaran distribusi hasil produksi tambang untuk pemuatan pasir kwarsa yang merupakan usaha pokok perusahaan. Selain terminal dibutuhkan pembangunan lapangan penumpukan guna mempermudah loading pasir kwarsa dari area penumpukan ke tongkang.

Hasil Survei Hidro Oceanografi.

Survei hidro oceanografi, digunakan untuk menentukan pasang surut air, arus, kedudukan pasang surut air tertinggi, tengah, rendah/lws, dengan pengamatan 15 hari secara berturut urut, pendataan dimulai dari pukul $00 .^{\circ o}$ waktu setempat pada hari pertama dan berakhir pada pukul 24. ${ }^{\circ o}$ hari ke 15 .

a. Hidrografi 
Dari hasil survey, dasar laut terdiri dari pasir dan bebatuan sepanjang alur berpasir, daerah tepi pantai merupakan daratan yang berbukit, ditumbuhi hutan kecil dan tanam tumbuh penduduk sekitar seperti perkebunan kelapa, durian, kelapa sawit, lada, cempedak dan tanaman keras lainnya.

Letak geografis tersus ditinjau dari pelayaran dan lalu lintas perairan pantai laut Bangka. Peta perairan laut Bangka dapat dilihat pada gambar di bawah :
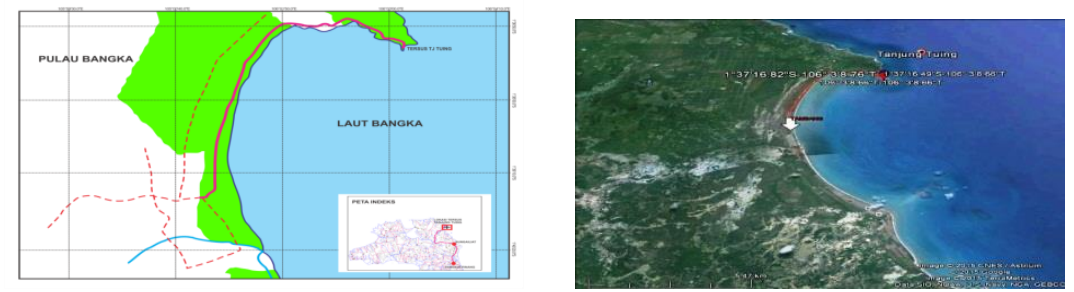

Gambar 7: Blue Peta Dan Peta Google Eart Perairan Laut Bangka Sumber : PT. Karya Cipta Bangka Lancar

b. Uraian Wilayah Perairan Terminal Khusus CV. Bina Lestari Jaya

1). Ke dalaman alur dari tempat labuh sampai ke tersus
a). Ambang luar labuh minimum/surut
$: 5,5 \mathrm{~m} \mathrm{Lws}$
b). Ambang luar Buoy hijau maksimum/ pasang
: $8,5 \mathrm{~m} \mathrm{Hws}$

(Ke dalaman di sepanjang alur tidak merata)

2). Ke dalaman depan kolam tersus :

a). Ke dalaman maksimum/pasang : 6,5 $\mathrm{m} \mathrm{Hws}$

b). Ke dalaman minimum/surut : $2,5 \mathrm{~m} \mathrm{Lws}$

c. Pasang Surut

(Ke dalaman di sepanjang kolam tergantung pasang surut)

Kawasan laut Tanjung Tuing pasang surut tunggal beraturan waktu, dari hasil pengamatan didapatkan pasang surut di daerah dermaga memiliki tipe pasang surut setengah harian ganda (semi diurnal). Dari data pasang surut didapatkan:
1). Perbedaan pasang surut sebesar
2). Waktu tolak GMT
: 2,6 $\mathrm{m}$ ( rata-rata )
3). Elevasi HWS (High Water Spring)
: -07.00
4). Elevasi LWS (Low Water Spring)
$: \pm 1.60$ M. Lws
$: \pm 0.00$ M. Lws.

d. Gelombang

Gelombang laut pada umumnya di seputaran laut Bangka pantai utara sampai ketinggian \pm 2 Meter (disaat angin barat).

Hasil penelitian studi pengukuran gelombang laut dilakukan pada titik penentuan berdasarkan pemamtauan lapangan dan menggunakan alat GPS, hasil yang didapat dalam program data melalui GPS dengan kecepatan rata 7- 10 knot.

Tabel 2 : Tinggi Dan Periode Gelombang Hasil Pengukuran Lapangan

\begin{tabular}{|c|c|c|c|c|c|c|c|c|}
\hline $\mathrm{Tgl}$ & $\begin{array}{c}\text { Hmax } \\
(\mathrm{m})\end{array}$ & $\begin{array}{c}\mathrm{Hs} \\
(\mathrm{m})\end{array}$ & $\begin{array}{c}\text { Hmin } \\
(\mathrm{m})\end{array}$ & $\begin{array}{c}\text { Hrerata } \\
(\mathrm{m})\end{array}$ & $\begin{array}{c}\text { T.max } \\
(\text { detik })\end{array}$ & $\begin{array}{c}\text { Ts } \\
(\text { detik })\end{array}$ & $\begin{array}{c}\text { T.min } \\
(\text { detik })\end{array}$ & $\begin{array}{c}\text { T.rerata } \\
(\text { detik })\end{array}$ \\
\hline 23 & 0,683 & 0,105 & 0,028 & 0,074 & 6,5 & 5,55 & 2,2 & 5,33 \\
\hline
\end{tabular}

Sumber : PT. Karya Cipta Bangka Lancar

Majalah Ilmiah Bahari Jogja 113 | http://jurnal.amy.ac.id/index.php/MIBJ/ 
Sedang tinggi gelombang peramalan, dapat dilihat gambar di bawah:

Tabel 3 : Periode Gelombang Peramalan

\begin{tabular}{lccc}
\hline \multicolumn{1}{c}{ Musim } & Signifikan (detik) & $\begin{array}{c}\text { Maksimum } \\
\text { (detik) }\end{array}$ & Minimum (detik) \\
\hline Barat & 2,105 & 3,512 & 1,395 \\
Peralihan 1 & 1,512 & 3,063 & 1,175 \\
Timur & 1,990 & 2,707 & 1,725 \\
Peralihan 2 & 1,818 & 2,670 & 1,574 \\
\hline
\end{tabular}

Sumber : PT. Karya Cipta Bangka Lancar

Sedang tinggi gelombang Tipikal dapat dilihat gambar di bawah:

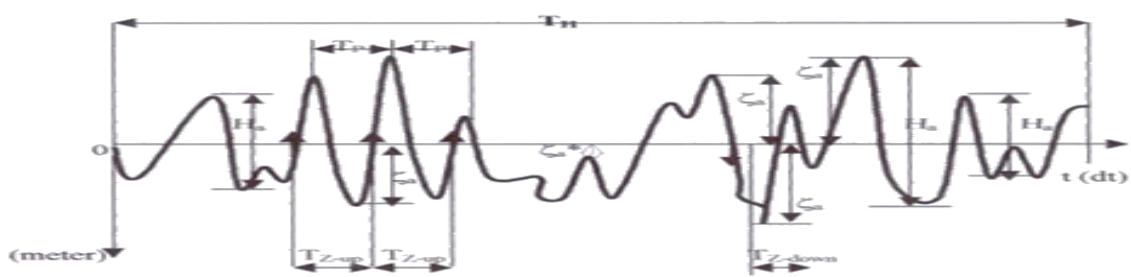

Gambar 8 : Gelombang Tipikal

Sumber : PT. Karya Cipta Bangka Lancar

e. Arus

Posisi arus pada alur pelayaran dengan kecepatan :

1). Kecepatan \pm 1,7 Knots (keadaan pada saat air surut)

2). Kecepatan $\pm 1,2$ Knots ( keadaan pada saat air pasang)

3). Arah arus di pantai variabel.

4). Kanal/terminal arah arus mengikuti pasang surut dengan kecepatan \pm 1,3 sampai 1,5 Knots. (tergantung cuaca).

Hasil survei tim lapangan perusahaan, salah satu dalam penentuan alur pelayaran, penentuan lokasi kolam putar (turning basin) dan ke dalaman berdasarkan $l w s / h w s$.

Data diperoleh dengan survei bathimetri, untuk mengetahui data kontur bawah laut dan menditeksi adanya karang di sekitar lokasi perairan, khususnya di area kolam pelabuhan /kolam putar, alur masuk dermaga untuk keselamatan pelayaran.

Dalam survei tim perusahaan didampingi oleh tim teknis dari Distrik Navigasi Kelas 1 Palembang. Hasil survei tim Distrik Navigasi mengeluarkan berita acara dan dikirim ke Kantor Otoritas Pelabuhan kelas IV Pangkalbalam sebagai pertimbangan keluarnya rekomendasi.

Hasil survei bathimetri berupa peta dengan menggunakan alat GPS garmin 858 di kawasan perairan tersus. Dengan skala yang memadai, proses sounding 
dilakukan di kolam dermaga guna menentukan alur masuk dermaga, titik pilot station. Gambar hasil survei bisa dilihat di bawah ini.
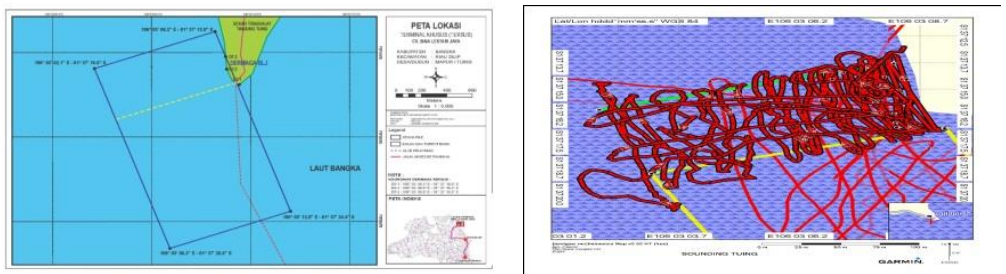

Gambar 9: Peta Lokasi Kolam Dermaga Dan Peta Sounding/Track Bathimetri Sumber : PT. Karya Cipta Bangka Lancar

Gambar di atas merupakan kolam dermaga tersus dengan pemetaan menggunakan alat GPS, dengan skala yang memadai, dari rencana kolam dermaga dilakukan sounding bathimetri perairan yang dijadikan kolam dermaga, track sounding kolam, peta track bathimetri di lokasi kolam dermaga, pemetaan menggunakan GPS garmin 858, dilengkapi sonar guna menditeksi keadaan bawah laut.

Proses sounding menggunakan perahu motor/boat, agar mudah bermanuver karena pemetaan harus sesuai dengan track yang ada di GPS, track tersebut harus dilewati, tidak boleh terlewatkan agar mendapatkan hasil kontur bawah laut yang valid. Proses sounding ini dimulai dari kade dermaga dengan laju boat horizontal sesuai track yang ada di GPS.

Hasil sounding berupa peta Kontur Bawah Laut, Peta Alur Pelayaran, Peta Arah Angin bisa dilihat pada gambar di bawah ini.
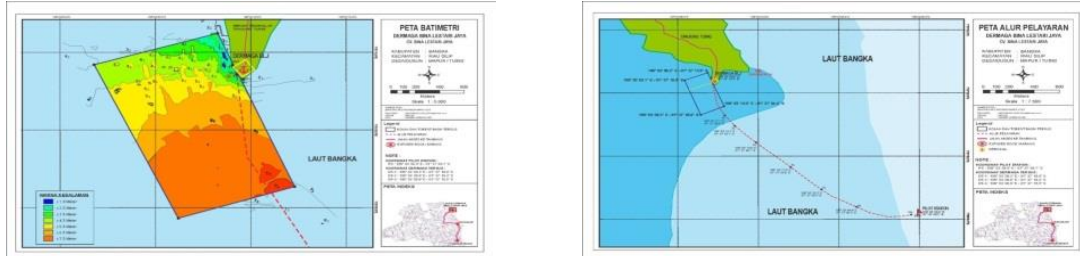

Sumber : PT. Karya Cipta Bangka Lancar

Gambar 11 : Peta Arah Angin Dan Peta Arus Air
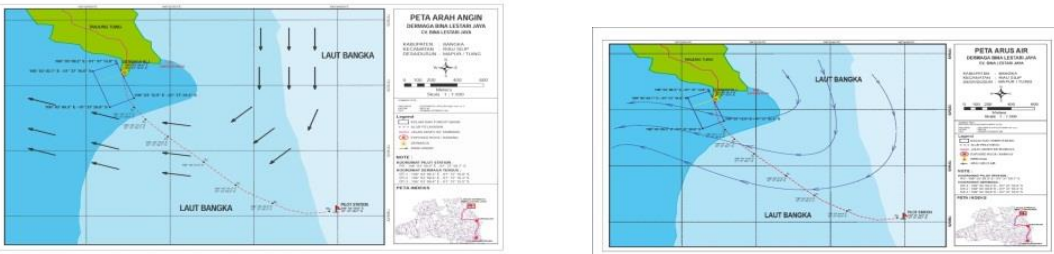

Gambar 10 : Kontur Bawah Laut Dan Peta Alur Pelayaran

Sumber : PT. Karya Cipta Bangka Lancar

Hasil studi kelayakan digunakan sebagai persyaratan telah terpenuhi dan mendapat rekomendasi, maka semua berkas dimasukan ke pemerintah daerah untuk proses mendapatkan ijin, baru kegiatan pembagunan dimulai.

Majalah Ilmiah Bahari Jogja 115 | http://jurnal.amy.ac.id/index.php/MIBJ/ 


\section{SIMPULAN}

Terminal khusus CV. Bina Lestari Jaya merupakan pembangunan tersus untuk menunjang kelancaran kegiatan bongkar muat hasil tambang. Usaha ini dapat memberikan kontribusi dengan pemberdayaan masyarakat sekitar. Persyaratan perijinan tersus dengan melakukan kajian studi kelayakan oleh tim perusahaan didampingi Syahbandar dan Distrik Navigasi dalam berbagai hal, seperti kajian ekonomi, lingkungan, alur pelayaran, ke dalaman kolam. Hasil studi menjadi pertimbangan oleh pejabat yang berwenang dalam memberikan perijinan.

Hasil survei hidro oceanografi menjadi kajian guna keamanan dan keselamatan pelayaran, dimana dalam survei bathimetri tim perusahaan didampingi oleh tim teknis dari Distrik Navigasi Kelas 1 Palembang. Pemantauan lingkungan secara rutin dilakukan, berupa pengujian kualitas air guna olah gerak dan manuver kapal, mempengaruhi kualitas air di sekitar kolam pelabuhan, pengujian tingkat kebisingan di sekitar pelabuhan yang ditimbulkan karena aktifitas di lokasi pelabuhan dan tingkat kandungan debu di sekitar area akses jalan yang dilalui truk dalam proses pengangkutan hasil tambang pasir kwarsa. Apabila semua persyaratan secara administrasi dan tehnis memenuhi, maka ijin pembanguanan tersus dikeluarkan.

\section{DAFTAR PUSTAKA}

Abas Salim, 1995, Manajemen Pelayaran Niaga Dan Pelabuhan, Cetakan Pertama, PT. Dunia Pustaka Jaya, Jakarta.

Bambang Triatmodjo, 2008. Pelabuhan, Beta Offset, Yogyakarta.

Sumardi, Djarwo Surjanto, Adi Hidayat, Ahmad Baroto, 2000, Refrensi Kepelabuhan Seri 4, Perencanaan Perancangan Dan Pembangunan Pelabuhan, Pelindo, Surabaya.

Singarimbun, Masri dan Sofian Effendi,1983, Metode Penelitian Survai, LP3ES, Jakarta

Moleong, Lexy J. 2005, Metodologi Penelitian Kualitatif, Remaja Rosdakarya, Bandung, edisi revisi

Nirnama,

RadarBangka,www.radarbangka.co.id/berita/detail/pangkalpinang/34421/p elindo-bangun-pelabuhan-khusus-komoditas-ekspor.html,

Purjiyono, Astriawati,N, P. S. S (2019) 'Perawatan Sistem Pelumasan Mesin Utama Pada Kapal Km. Mutiara Sentosa II’, Teknovasi, 06, pp. 74-80.

Republik Indonesia. 2007. Undang-Undang Republik Indonesia Tentang Pembagian Urusan Pemerintahan Antara Pemerintah, Pemerintah Daerah Provinsi, Dan Pemerintah Daerah Kabupaten/ Kota. Lembar Negara RI Tahun 2008,No 38. Sekertariat Negara. Jakarta. 
Republik Indonesia. 2008. Undang-Undang Republik Indonesia Tentang Pelayaran. Lembar Negara RI Tahun 2008, No 17. Sekertariat Negara. Jakarta.

Republik Indonesia. 2015. Undang-Undang Republik Indonesia Perubahan Kedua Atas Undang- Undang Nomor 23 Tahun 2014 Tentang Pemerintah Daerah. Lembar Negara RI Tahun 2015,No 9. Sekertariat Negara. Jakarta.

Republik Indonesia. 2015. Peratur

an menteri Tentang Persyaratan Kepemilikan Modal Badan Usaha Di Bidang Transportasi. Lembar Negara RI Tahun 2015,No 45. Sekertariat Negara. Jakarta

Repulik Indonesia. 2014. Peraturan Menteri Tentang Perubahan Atas Paraturan Menteri Nomor PM 51 Tahun 2011 Tentang Terminal Khusus Dan Terminal Untuk Kepentingan Sendiri. Lembaran Negara RI Tahun 2014, No. 73. Sekertariat Negara. Jakarta.

PT. Karya Cipta Bangka Lancar, Bangka Belitung. 